World Maritime University

The Maritime Commons: Digital Repository of the World Maritime University

\title{
Development of online education and its applicationin Shanghai Maritime University
}

\author{
Xin Shi \\ Shanghai Maritime University \\ Yingming Wang \\ Shanghai Maritime University \\ Hui Zhuang \\ Shanghai Maritime University \\ Zekun Zhang \\ Shanghai Maritime University
}

Follow this and additional works at: https://commons.wmu.se/imla2021

Part of the Education Commons

\section{Recommended Citation}

Shi, X. , Wang, Y. , Zhuang, H. \& Zhang, Z. (2021). Development of online education and its application in Shanghai Maritime University. In Pazaver, A., Manuel, M. E., Bolmsten, J., Kitada, M., Bartuseviciene, I. (Eds.), Proceedings of the International Maritime Lecturers' Association. Seas of transition: setting a course for the future (pp. 218-225). World Maritime University. http://dx.doi.org/10.21677/imla2021.19

This Paper is brought to you courtesy of Maritime Commons. Open Access items may be downloaded for noncommercial, fair use academic purposes. No items may be hosted on another server or web site without express written permission from the World Maritime University. For more information, please contact library@wmu.se. 
http://dx.doi.org/10.21677/imla2021.19

\title{
Development of online education and its application in Shanghai Maritime University
}

\author{
Xin Shi \\ Professor, Shanghai Maritime University, Shanghai, China, xinshi@shmtu.edu.cn \\ Yingming Wang \\ International Officer, Shanghai Maritime University, Shanghai, China, \\ ymwang@shmtu.edu.cn \\ Hui Zhuang \\ PhD Candidate, Shanghai Maritime University, Shanghai, China \\ zhuanghui@stu.shmtu.edu.cn

\section{Zekun Zhang} \\ Postgraduate Candidate, Shanghai Maritime University, Shanghai China, \\ 202030610030@stu.shmtu.edu.cn
}

\begin{abstract}
Online teaching is becoming an important alternative approach to maritime education, which traditionally relies on face-to-face instruction, particularly during the period when the COVID-19 has had a devastating impact on the educational system worldwide. On the base of the conceptualization of online education through a literature review, this study demonstrates the case of an innovative online teaching system developed and implemented by Shanghai Maritime University (SMU) that successfully allowed some 20,000 students to resume learning despite the COVID-19 disruption. To realize large-scale online teaching, four phases of development the SMU underwent are introduced. The whole process of planning, preparation, implementation as well as evaluation is elaborated. In addition to class teaching, other major activities delivered remotely are also introduced, including short-term training programs, graduation ceremony, online career fairs, online interviews for postgraduate admission. Difficulties and challenges in shifting to the new teaching method and how SMU developed effective strategies to solve these issues are addressed. This study provides a valuable example of an online teaching system realized in a maritime institution. Furthermore, it may serve as an inspirational reference to peer maritime institutions to adopt or improve their competence of online learning systems.
\end{abstract}

Keywords: online education, teaching model, smart teaching ecology

\section{Introduction}

With the rapid development of information and network technology, online education, a novel education model in which students can join classes at home using computers, or mobile phone devices as long as the internet is accessible, has received increasing recognition. Coşofreț and Avram (2020) highlighted the positive aspects specific to maritime online education, including offering quality technical didactic, properly planned teaching activities, and efficient collaboration between students and professors. Cherry and Flora (2017) argued such 
effectiveness could be improved with experience in teaching online courses and competence with use of technology, and faculty members with technological self-efficacy were more likely to use technology-enhanced learning methods in the online environment. Doyumgaç et al. (2021) highlighted that quality, flexibility, sensitivity of online education, communication and technical support services, and so on could positively affect student's perceptions of online education. A questionnaire survey designed by Huang (2020) revealed most teachers and students are content with online teaching based on the significant support from technologies and platforms.

Specifically, the significance of online education has been fully demonstrated in fighting the COVID-19 pandemic. The pandemic has brought devastating disorder to the educational system worldwide. Online education is the most efficient way to cope with the lecturing problem caused by such disruption, which is also supported by Aguilera-Hermida (2020). A survey of 15,438 Chinese teachers conducted by Yang (2020) indicated that most teachers are willing to support online education as an epidemic prevention and control initiative. Online education is therefore becoming an important alternative approach to education, which traditionally relies on face-to-face instruction.

In spite of these advantages, without a normative conceptual construction, online education is still diverse and case-by-case. Therefore, several key fundamental issues merit attention, such as architecture configuration, platform selection, standardization of teaching model, and intercommunication between teachers and students.

Based on this concern, a case study of an innovative online teaching system developed and implemented by the Shanghai Maritime University (SMU) that successfully allowed some 20,000 students to resume learning despite the COVID-19 disruption is presented. Based on the case study, this study (1) provides a conceptual framework of online education and (2) proposes suggestions for the development of online education.

The rest of this paper is organized as follows. Section 2 presents the conceptualization of online education, together with a literature review. Section 3 is a case study, which outlines the implementation of online education in SMU. Finally, a discussion and the conclusion are presented in section 4 .

\section{Conceptualization of online education}

Normally, the construction of online education should include four steps: (1) making a teaching plan, (2) preparing at technical level, (3) implementing the teaching plan, and (4) arranging online examination and evaluation.

Based on the aforementioned process, several key elements can be clarified: platform, function, situation, and model.

First, a suitable platform, which functions as the online meeting tool used for intercommunication learning, is the foundation for the smooth implementation of online education. At present, Zoom, Tencent Meeting, Zhumu, DingTalk, and so on are the most popular platforms.

Second, the multiple functions can be provided by online education. Lecturing materials including pictures, videos, and courseware can be presented simultaneously on the terminals 
of teachers and students. Real-time communication between the teacher and students or among students can be achieved, and online exams can be conducted under a comprehensive online invigilation mechanism.

Third, the application situation reveals the multiple manifestations of online education, which is not limited to class teaching but can also be extended to online interview, online seminar, and online communication.

Fourth, the online education models are also diversified and can be divided into four types: synchronous live class-based, asynchronous recording and broadcast, online flipped classroom, and online tutoring-based teaching models (Xue, 2020). More macroscopically, it can be classified into normal online learning, online learning without teachers' control, and online learning with group discussion (Root and Rehfeldt, 2020). In practice, synchronous live class and asynchronous recording videos are the most frequently used; herein, the former one is a model with the simultaneous presentation of teachers and students online, while the latter is that with the prerequisite that teachers have uploaded the learning video recorded before the class.

Based on aforementioned conceptual framework, benefits, other than flexibility, of online education are continually discovered, such as saving time and cost in the aspect of commuting and tuition (Behzadi and Ghaffari, 2011), solving the problem of inadequate classroom (Behzadi and Ghaffari, 2011), enhancing diversity and equity among students regardless of the living area and the performance (Afrouz and Crisp, 2020), and helping teachers switch to be a leader and accompanier rather than only the role of transmitting knowledge (Yao et al., 2020). However, some disadvantages and flaws were revealed, such as resulting in no campus life as specific library, classrooms, or communal areas that generate an atmosphere of campus culture are not available (Behzadi and Ghaffari, 2011), making it hard for teachers to control the teaching progress and content for students when they are at different levels (Chen et al., 2020; Yan et al., 2021; Butnaru et al., 2021). In addition, the security and quality of internet connection may be a conclusive factor that affects the process of online education (Zhao, 2020).

Therefore, some suggestions were proposed to cope with the flaws and improve the efficiency of online education. The development of "Web 2.0" could enrich the function and content of online library and make online education more convenient (Maness, 2006; Ram et al., 2011). Similarly, the enrichment of online education may compensate for the lack of campus life to some extent, and the improvement of internet technologies would enhance the security of online education. Furthermore, "AI teachers" are becoming popular (Kim et al., 2020), helping to improve the efficiency of Q\&A sessions as some questions with constant answers can be determined by AI teachers (Guilherme, 2019).

\section{Case description}

Located in Shanghai, SMU is a multi-disciplinary university with special emphasis on shipping, logistics, and oceans. At present, SMU has nearly 1,300 full-time teachers and over 26,600 full-time students, of whom over 16,000 are undergraduates and over 7,200 are postgraduate students. The daily teaching task of the whole school is busy but orderly. Therefore, the COVID-19 pandemic has undoubtedly posed a huge challenge to the regular operation of the university. SMU has taken full advantage of the online education structure mentioned above, and successfully allowed some 20,000 students to resume learning. Through such a practical 
case, the specific implementation operations, effectiveness, and development direction can be reasonably concluded.

\subsection{Promotion process}

The structure of promotion of SMU online teaching is illustrated in Figure 1.

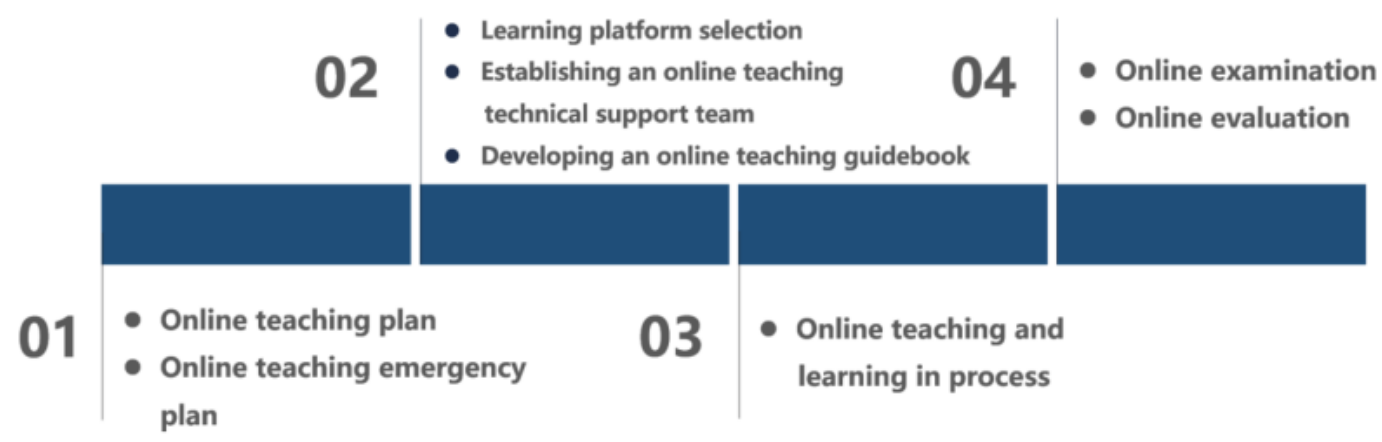

Figure 1. Structure of promotion of online education

\section{Planning}

To conduct online education successfully, a well-prepared teaching plan and emergency teaching plan are necessary. Although the pandemic has had an unprecedented impact on education, the planning at SMU dismissed students' and teachers' concerns and has shifted teaching onto a new track.

\section{Preparation}

The preparation process of SMU online education is as follows. First, proper selection of online education platform is key to success, and a robust platform can save teaching and material resources as well as achieve satisfaction of teachers and students. Second, SMU has established an online teaching technical team to deal with any emergencies that may arise. When something goes wrong during the teaching process, the team can fix the problems as soon as possible to maintain the regular order. Lastly, developing an online teaching guidebook is also important. The online guidebook of SMU provides brief instructions that have enabled online education to be standardized.

\section{Implementation}

Teachers at SMU can upload the asynchronous recording videos to the online platform or conduct a synchronous live class to convey knowledge to students. Students should attend the class on time when the synchronous live class begins. Meanwhile, students are able to choose courses they are interested in and learn from the asynchronous recording videos (Cherry and Flora, 2017).

\section{Evaluation}

After finishing a period of learning, students' mastery of knowledge should be tested. Just as traditional examinations, the form of online examination is also an important method to check the learning outcomes. It is a key method to evaluate the success of online education. 


\subsection{Online teaching model}

The online teaching system was designed by SMU to convey knowledge from teachers to students via internet transmission by telecommunication technology. The topological structure of online teaching system of SMU is presented in Figure 2.

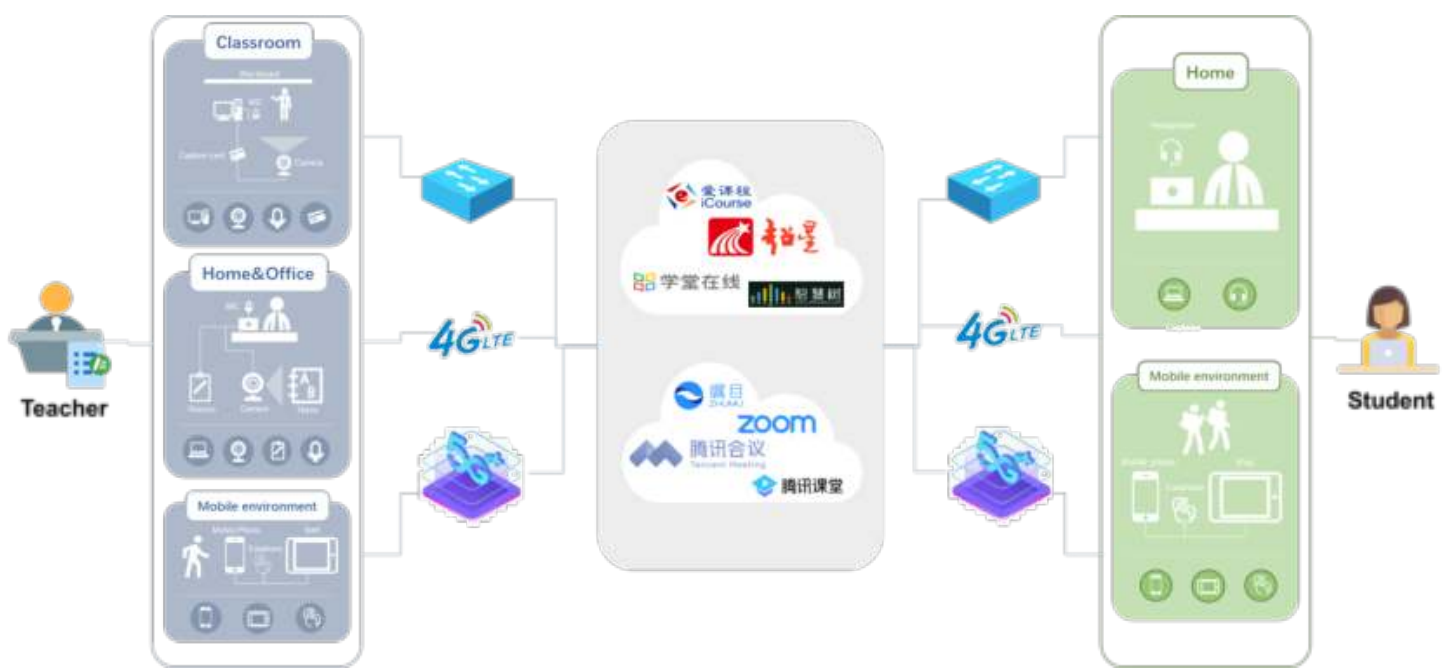

Figure 2. Topological structure of online teaching system of SMU

To mitigate the impact of COVID-19, learning continued via the online platform. Teachers prepared lessons at home and created a virtual class using a computer or mobile devices such as smartphones or pads. Mature online education platform such as iCourse, Chaoxing, and many meeting platforms such as Zhumu and Tencent. Homework assigned by teachers can be uploaded to the platform by telecommunication technology and students can receive tasks by logging on to the platform. In this way, teachers and students can conduct real-time communication via the platform.

According to statistics from the SMU Teaching Center, from February 2020 to July 2020, SMU online teaching for undergraduate students was promoted among teaching faculty members. In total, 735 teachers and some 12,500 students attended online teaching and an average of 2,469 classes were delivered per day. The learning resources uploaded include over 10,000 items and more than 16,000 classroom activities were conducted. Regardless of the scale of attending staff or the volume of learning material delivered.

In addition to undergraduate online teaching, the online learning method also successfully applies to short-term training programs, graduation ceremony, online career fairs, online interviews for postgraduate admission, and international conferences. The postgraduate admission interview was different from the previously used model. The traditional admission interview was face-to-face and written examination is also an essential part (Xiao and Li, 2020). However, online interviews were mainly focused on interviews rather than written examinations. This could comprehensively test the interviewee's ability regarding logic and expression. Additionally, an online career fair provided opportunities for graduates to meet potential employers and help graduates find jobs (Wang, 2021).

\section{Discussion \& conclusion}




\subsection{Advanced infrastructure support}

To support online teaching, advanced infrastructures consisting of intelligent classrooms, ubiquitous learning space, and cloud class production centers are essential and important.

In terms of the intelligent classroom, it always adopts a movable layout and is equipped with modern audio-visual technologies, such as multi-screen display, electronic whiteboard, and resource sharing tools. To provide a discussion and interactive teaching environment for various teaching scenarios such as lecture, group learning, and project exploration, SMU employs the complete set of facilities mentioned above.

The aspect of ubiquitous learning space is composed of course platform, offline facilities, and cloud desktop to meet students' personalized ubiquitous learning needs. In SMU, the course platform integrates 15,000 online courses, 1 million kinds of electronic books, 100,000 academic videos, and 3 million teaching documents. The online learning space is also extended to the offline with advanced facilities. Meanwhile, the cloud class production center is where quality classes are produced, and requires corresponding physical space and hardware. In the case of SMU, it possesses more than 200 square photographic space, more than 15,000 class hours of video production experience, and a professional team with more than 10 people. It shows the teaching resources production ability integrating virtual photography, live-action shooting, teaching discussion, and post-editing.

\subsection{Innovative teaching model}

Accordingly, an innovative teaching model should be developed to match the advanced infrastructure support and meet online education demands. Such a teaching model must consist of three parts corresponding to three phases of a class. First, before class, teachers should prepare lessons online, set learning tasks, and send them to students, while students are required to complete pre-class tasks online. Second, during the class, group cooperation, peer teaching, puzzle discussion, and other teaching interactions could easily be achieved with the help of modern education technology. Third, after class, teachers should check students' learning data to master the progress and effect of learning, and students can make use of the platform resources to conduct independent exploration and realize the expansion and extension of knowledge.

In 2019, 25 SMU teachers took the lead in adapting to the classroom teaching reform based on the smart teaching ecology and offered 25 trial courses. The entire school curriculum was gradually extended to promote the transformation from the traditional teaching-oriented classroom to the intelligent interactive-oriented classroom. In 2020, relying on the smart teaching ecology, the university's online teaching activities were able to run smoothly during the COVID-19 pandemic.

\subsection{Conclusion}

In conclusion, the COVID-19 pandemic has accelerated the development of online education, which implies an innovative teaching model. Based on the conceptual framework of online education and referring to the implementation case of SMU, focusing on "intelligent classroom teaching" integrated by the implementation of teaching, learning, management, sharing, interaction, and achieving the reconstruction of learning space, teaching process and academic evaluation are essential for online education. The pattern of SMU online education can be 
consulted, first starting from the establishment of the advanced infrastructure which includes intelligent classroom, ubiquitous learning space, and cloud class center; then achieving the transition from "passive learning by traditional classroom instruction" to "the inquiry learning by doing." Through reconstructing teaching scenarios, extending learning space, and focusing on course construction.

\section{Acknowledgments}

Sincere thanks to our SMU colleagues, the Electronic Teaching Assistant Team in particular. This study is the summary of their pioneering work on the implementation of e-learning in SMU. Without their generous sharing of knowledge and experience, this study would not be possible.

\section{Reference}

Afrouz, R., \& Crisp, B. R. (2020). Online Education in Social Work, Effectiveness, Benefits, and Challenges: A Scoping Review. Australian Social Work, 74(1), 55-67. doi:10.1080/0312407x.2020.1808030

Behzadi, Z., \& Ghaffari, A. (2011). Characteristics of online education and traditional education. Life Science Journal, 8(3), 54-58.

Butnaru, G. I., Niță, V., Anichiti, A., \& Brînză, G. (2021). The Effectiveness of Online Education during Covid 19 Pandemic-A Comparative Analysis between the Perceptions of Academic Students and High School Students from Romania. Sustainability, 13(9), 5311.

Chen, T., Peng, L., Yin, X., Rong, J., Yang, J., \& Cong, G. (2020). Analysis of User Satisfaction with Online Education Platforms in China during the COVID-19 Pandemic. Healthcare, 8(3), 200. doi:10.3390/healthcare8030200

Cherry, S. J., \& Flora, B. H. (2017). Radiography faculty engaged in online education: Perceptions of effectiveness, satisfaction, and technological self-efficacy. Radiologic Technology, 88(3), 249-262.

Coșofreț, D., \& Avram, E. R. Evaluation of the Maritime Higher Education didactic support during the coronavirus pandemic. Case Study. The 15th International Conference on Virtual Learning ICVL 2020, 493-499.

Doyumgaç, I., Tanhan, A., \& Kiymaz, M. S. (2021). Understanding the most important facilitators and barriers for online education during COVID-19 through online photovoice methodology. International Journal of Higher Education, 10(1), 166-190.

Guilherme, A. (2019). AI and education: the importance of teacher and student relations. Ai \& Society, 34(1), 47-54.

Huang, J. (2020). Successes and Challenges: Online Teaching and Learning of Chemistry in Higher Education in China in the Time of COVID-19. Journal of Chemical Education, 97(9), 2810-2814. doi:10.1021/acs.jchemed.0c00671

Kim, J., Merrill, K., Xu, K., \& Sellnow, D. D. (2020). My Teacher Is a Machine: Understanding Students' Perceptions of AI Teaching Assistants in Online Education. International Journal of Human-Computer Interaction, 36(20), 1902-1911. doi:10.1080/10447318.2020.1801227

Maness, J. M. (2006). Library 2.0 theory: Web 2.0 and its implications for libraries. Webology, $3(2)$. 
Patricia Aguilera-Hermida, A. (2020). College students' use and acceptance of emergency online learning due to COVID-19. International Journal of Educational Research Open, 1, 100011. doi:10.1016/j.ijedro.2020.100011

Ram, S., Paul Anbu K, J., \& Kataria, S. (2011). Responding to user's expectation in the library: innovative Web 2.0 applications at JUIT Library. Program, 45(4), 452-469. doi:10.1108/00330331111182120

Root, W. B., \& Rehfeldt, R. A. (2020). Towards a Modern-Day Teaching Machine: The Synthesis of Programmed Instruction and Online Education. The Psychological Record, 71(1), 85-94. doi:10.1007/s40732-020-00415-0

Wang, J. (2021, March). Analysis on the Influence of Economic Shock on the Employment of Higher School Students Under the Epidemic situation. In 6th International Conference on Financial Innovation and Economic Development (ICFIED 2021) (pp. 718-721). Atlantis Press.

Xiao, C., \& Li, Y. (2020). Analysis on the Influence of the Epidemic on the Education in China. 2020 International Conference on Big Data and Informatization Education (ICBDIE). doi:10.1109/icbdie50010.2020.00040

Xue, E., Li, J., \& Xu, L. (2020). Online education action for defeating COVID-19 in China: An analysis of the system, mechanism and mode. Educational Philosophy and Theory, 1-13.

Yan, L., Whitelock-Wainwright, A., Guan, Q., Wen, G., Gašević, D., \& Chen, G. (2021). Students' experience of online learning during the COVID-19 pandemic: A province-wide survey study. British Journal of Educational Technology.

Yang, X. (2020). Teachers' Perceptions of Large-Scale Online Teaching as an Epidemic Prevention and Control Strategy in China. ECNU Review of Education, 3(4), 739-744. doi:10.1177/2096531120922244

Yao, J., Rao, J., Jiang, T., \& Xiong, C. (2020). What role should teachers play in online teaching during the COVID-19 pandemic? Evidence from China. Sci Insigt Edu Front, 5(2), 517-524.

Zhao, Y. (2020). Social Learning and Learning to Be Social: From Online Instruction to Online Education. American Journal of Education, 127(1), 137-142. doi:10.1086/711017 